\title{
Filosofía universitaria: una corriente para la construcción de significados en la formación de formadores
}

\author{
Fecha de recepción : 19-10-2020 • Fecha de aceptación: 02-03-2021 • Fecha de publicación: 10-05-2021
}

Henry Jose Martínez González'

Universidad Nacional Experimental Rafael María Baralt, Venezuela

mgjhenry@hotmail.com

https://orcid.org/0000-0001-8929-4508

Duglas Ramón Piña Madueño²

Universidad Nacional Experimental Rafael María Baralt, Venezuela

Duglasrpm03@gmail.com

https://orcid.org/0000-0003-3868-9045

Juhenni María Martínez González ${ }^{3}$

Universidad Nacional Experimental Rafael María Baralt, Venezuela

juhenny_maria@hotmail.com

https://orcid.org/0000-0001-5527-5181

\section{Resumen}

La educación es concebida como una filosofía orientada a los procesos formativos, donde los desconocimientos de quienes ejercen la profesión docente se han visto descontextualizada de sus fines, cuyo propósito fue develar la filosofía universitaria como una corriente para la construcción de significados en la formación de formadores. Esta investigación se orientó en los autores Castells (2009), Monge et al., (2003) con un enfoque cualitativo y fenomenológica, con el uso de entrevistas y un guion, a manera de triangulación. Como resultado, muchos de los docentes hacen uso incorrecto del poder en sus aulas, pues esta actitud conlleva a los estudiantes a realizar sus actividades de forma limitada, puesto que se les impone la estructura, el discurso, entre otros factores cognitivos. Por último, se concluye que las herramientas para un aprendizaje y enseñanza casi nunca conllevan a reflexionar sobre la actuación del docente como del estudiante, por su parte, la formación carece de 
estrategias para el enseñar a pensar desde el aprender a ser, aprender hacer y aprender a aprender, generando entonces propuestas transformadoras en concordancia con las políticas educativas emanadas por el Estado Venezolano.

Palabras clave: profesión docente, filosofía universitaria, formación de formadores, construcción de significados.

\begin{abstract}
Education is conceived as a philosophy oriented to formative processes, where the lack of knowledge of those who exercise the teaching profession has been decontextualized from its purposes, whose purpose was to unveil the university philosophy as a current for the construction of meanings in the training of trainers. This research was guided by the authors Castells (2009), Monge et al., (2003) with a qualitative and phenomenological approach, with the use of interviews and a script, by way of triangulation. As a result, many teachers misuse power in their classrooms, as this attitude leads students to perform their activities in a limited way, since structure, discourse, among other cognitive factors, are imposed on them. Finally, it is concluded that the tools for learning and teaching almost never lead to reflect on the performance of the teacher and the student, for its part, the training lacks strategies for teaching to think from learning to be, learning to do and learning to learn, generating then transforming proposals in accordance with the educational policies issued by the Venezuelan State.
\end{abstract}

Keywords: teaching profession, university philosophy, training of trainers, construction of meanings 


\section{Introducción}

Desde una perspectiva inicial, los estudios relacionados con los aportes científicos filosóficos constituyen una actividad generadora de nuevos elementos indispensables en describir significados que coadyuven en aclarar símbolos o códigos representativos de los discursos propios de actores sociales quienes interactúan el en comportamiento de un fenómeno, todo ello, con la finalidad de plantear supuestos teóricos para propiciar la construcción de ideas, pensamientos y conocimientos orientados en desarrollar un proceso educativos cónsono con la realidad actual, en este sentido, promover estrategias viables en la liberación de un modelo formativo dirigido a gestionar el liderazgo además de la toma de decisiones a través de la elaboración de propuestas transformadoras, a su vez, pretenden asumir posturas de cambios acordes a las demandas y exigencias de la sociedad donde la ciencia y la tecnología ocupan un papel importante en el avance de propuestas para innovar así como crear nuevos mecanismos en sincronía con las reconfiguraciones, retos y desafíos producto de la globalización y la era digital,

Por consiguiente, el trabajar bajo la perspectiva del pensamiento complejo y emancipador implica la construcción de teorías o contenidos con un nivel de profundidad donde la actividad científica e investigativa permita cimentar nuevos atributos conceptuales, en efecto, la acción dialógica y comunicativa conlleva el estudio de fenómenos desde la perspectiva crítica reflexiva a fin de en la emancipación de las ideas y con ello edificar conocimientos que vayan en relación a las políticas educativas del Estado venezolano.

En este sentido, el presente estudio pretende comprender la filosofía universitaria como una corriente para la construcción de significados en la formación de formadores, a su vez, se hace necesario estudiar un conjunto de fuentes de teorías propias para fundamentar los discursos expresados por los investigadores, de esta manera, se propician procesos de argumentación a partir de las observaciones propias, todo ello, con la finalidad de recorrer los comportamientos a partir de situaciones históricos que van mostrando cómo los docentes de las universidades limitan la libertad de pensamiento de los estudiantes, imponiendo así sus estilos, más no realizando procesos de orientación y acompañamiento de las actividades científicas y de investigación.

\subsection{Transcendencia del conocimiento: una visión comunicativa para el aprendizaje autoritario o humanista}

Desde la concepción de Castells (2009), el aprendizaje autoritario o humanista muchas veces se ven condicionado e influenciado por las situaciones de poder que se presentan en las organizaciones entre los actores involucrados en las mismas, por ello, la dominancia y empoderamiento en las acciones del otro representa actitudes que demarcan el poder, pues algunas veces, se genera satisfacción además del placer producto del sentir los derechos de ejercer el mandato ante sus subordinados. Asimismo, a través de un trabajo de campo en las asesorías de los proyectos de investigación en el nivel de pregrado muchos docentes disfrutan de las debilidades que presentaban los estudios debido a las pocas explicaciones, de igual manera, este avance se veía afectado ya que casi nunca se ejemplificaban las etapas o fases a seguir para lograr los objetivos, por otra parte, en otros departamentos o áreas del conocimiento se evidenciaba en las reuniones docentes el poder por ver quien sabia más, lo ilógico no era eso, sino 
que unos eran humillados por no haberse memorizado ciertos libros, razón por la cual, se veía la posesión de ideas basadas más en los aportes de teóricos que las interpretaciones que pudieran haber hecho los mismos para contextualizar las mismas, estas visiones emergen de la Universidad Nacional Experimental "Rafael María Baralt” (UNERMB) de Venezuela.

Haciendo referencia, a lo mencionado por el autor antes citado, se expone que para él, el poder asume un papel de jerarquía el cual las acciones de liderazgo se ven afectadas debido a la poca participación de los subordinados en las propuestas de planes y proyectos requeridos para promover una actividad de calidad, desde la perspectiva universitaria este se ve muy arraigado ya que pocas veces se establecen relaciones entre los docentes y directivos, solo cuando de estos requerían alguna acción o información. Pero el mismo autor, comenta la posibilidad de estudiar esta naturaleza a partir de resistencias a los cambios transformadores e innovadores sin estar de acuerdo con las ideas de sus subordinados, hablamos entonces de cegueras que limitan la perspectiva de los otros.

En este mismo orden de ideas, existe la imposición del poder por parte de la mayoría de docentes en cuanto a la fijación de posturas antes los discursos de los estudiantes, ejemplo, en evaluaciones con preguntas abiertas o trabajos de análisis e interpretación sus sugerencias son pocos objetivas, ya que, se evidencia que carecen de criterios para exponer las ideas irrespetando la capacidad de pensamiento del otro, estas acciones, generan en los estudiantes, desinterés, desmotivación y muchas veces deserción ya que nunca ven el avance o progreso de su aprendizaje. Por ellos, se ven limitados al pensamiento liberador, por el contrario, buscan repetir lo que está en los textos, es decir, pocas veces conducen a la construcción de nuevas ideas para promover conocimientos a partir de sus experiencias. En este orden de ideas, Castells (2009), hace referencia a dos teorías de poder: el discurso y la violencia, para ello, la primera obedece al conocimiento donde se cree que por tenerlo o tener más que los otros se puede asumir un papel de menos preciar, por otro lado, la segunda está referida al maltrato por representar una jerarquía, perdiéndose allí el sentido del enfoque humanista que caracteriza el sector educativo en la formación del nuevo ciudadano.

Por otra parte, Habermas (1976), plantea que una de las posesiones del poder sobre los actores sociales está dirigida a los postulados referidos en la teoría política la cual genera en los gobernantes o personas con altos cargos ejercer situaciones dominantes donde los menos agraciados deben responder a las instrucciones sin poder opinar ni refutar ante algún desacuerdo. En este sentido, El transformar esta postura, permitiría a las organizaciones promover estrategias de integración para de esta manera promover el trabajo en equipo donde el liderazgo sea visto como una actitud para promover cambios favorables en el bien común de todos los trabajadores sin importar los títulos, condiciones socioeconómicas, entre otras, es decir, diseñar procesos y procedimientos que avancen a una democracia desde la práctica y no desde la teoría.

Al respecto, los docentes requieren y necesitan establecer normas y pautas de convivencia escolar-institucional dentro de los espacios de aprendizajes, con la finalidad de generar acuerdos consensuados entre los estudiantes, proponiendo para ello criterios de objetividad que permitan y faciliten el desarrollo integral de las actividades académicas, así como también el fomento de valores personales y profesionales como la ética y el respeto por los demás. Todo ello 
contribuirá en la construcción propia y colectiva de los saberes mediante el dialogo, donde se definan percepciones e ideas sobre temas relacionados con las asignaturas estudiadas y su inferencia en los cambios educativos para diseñar, proponer y/o formular estrategias, acciones o lineamientos transformadores de la realidad socioeducativa promoviendo de esta forma la reflexión y participación democrática de los conocimientos.

\subsection{Las redes sociales de comunicación}

La sociedad de la información ha contribuido esencialmente en la generación de nuevas estrategias y metodologías conducentes a facilitar el acceso al conocimiento, de allí se promueven espacios dinámicos para la interacción e intercambio de ideas, en tanto, Monge et al., (2003), manifiestan que las estructuras o edificaciones de redes facilitan el acceso a la información y, por ende, al conocimiento permitiendo así en los participantes del contexto educativo poder interactuar además de dinamizar los encuentros de aprendizaje mediante tiempos iguales o diferentes, en este sentido: "las redes de comunicación son las pautas de contacto creadas por el flujo de mensajes entre distintos comunicadores en el tiempo y en el espacio" (p.39). Es decir, las redes procesan flujo, los cuales son definidos como corrientes de información entre nodos que circulan por los canales que conectan los mismos. Por lo que una red está definida por el programa que asigna los objetivos y las reglas de funcionamiento propio de la red.

Asimismo, las universidades requieren masificar la información para permitir el acceso al conocimiento considerando para ello el avance de la ciencia, la tecnología y los cambios generados en la sociedad para el mejoramiento de los proceso tradicionales con la finalidad de estar a la vanguardia de las demandas como exigencias que implica contribuir a la nación, más allá, de esclavizar a quiénes poseen pocas o ideas o les hacen ver como inferiores a los demás, la formación integral a través de la culturización general del pensar facilita la liberación del pensamiento brindando así herramientas para la gestión del conocimiento con actores sociales de diferentes contextos educativos.

De igual forma, Mokyr (1990), expone que el alcance de la información a través de las redes orienta la actualización de las ideas mediante el intercambio de saberes con la finalidad de crear nuevas experiencias que conlleven a la transformación del pensamiento, el cual deslinde el uso de este para dominar sino para innovar en las estrategias que garanticen la producción intelectual como científica, para de esta manera, evolucionar en el manejo didáctico/pedagógico de las tecnologías de la comunicación en consonancia con las múltiples aplicaciones que forman parte de la dinámica e interacción de las ideas.

Todo ello obedece a los cambios políticos, económicos, históricos y especialmente culturales, ya que son estos factores influyen y definen a los actores sociales en su proceso de actuación ante los diversos retos que demanda y exige la sociedad, puesto que la identificación cultura de las comunidades puntualiza el comportamiento de las estructuras sociales y con ello los valores y creencias que dan forma y orientan dichas conductas propias de sus cambios globales, pudiéndose decir, que estos influyen de forma tal que define sistemas de relaciones entre las personas o individuos que conviven en un contexto determinado. 


\subsection{Sociedad tecnológica: una visión para comunicar y mejorar los procesos gerenciales educativos}

Se puede entender como espacios o contextos aplicados a la era digital a un mundo tecnológico en que convergen múltiples alternativas para desarrollar actividades cónsonas con la labor de las organizaciones, a fin de innovar la aplicabilidad de los procesos tradicionales, en efecto, Schiller (2006), sostiene que la acción de comunicar refiere a un proceso multidireccional donde la tecnología de la comunicación representa un canal primordial para enmarcar lineamientos fundamentales para representar canales, códigos, símbolos indispensables para decodificar o codificar señales que propicien avance del pensamiento liberador. De allí que, "el significado sólo puede comprenderse en el contexto de las relaciones sociales en las que se procesan la información y la comunicación”.

Del mismo modo, los procesos formativos en las universidades conducen a la reafirmación del poder pues los estudiantes pocas veces pueden participar de las actividades establecidas por el docente, es decir, deben hacerlas asumiendo cualquier instrucción sin salirse de la línea demarcada para su evaluación, por otra parte, la organización de las aulas evidencia el poder sostenido en el docente quien por tener grados académicos superiores se considera el de mayor jerarquía, en efecto, romper con estas estructuras garantizara el desarrollo integral de los ciudadanos y ciudadanas quienes poseen de manera igual potencialidades y habilidades valiosas además de aportar significados propios pertinentes a la transformación del pensamiento.

En este sentido, el acceso de la información implica la conexión de redes de internet para propagar o difundir contenidos para el estudio colaborativo y cooperativo entre los que ingresan a diferentes medios de comunicación como parte de su crecimiento personal así como profesional, por tanto, estas fortalecen muchas veces la discusión o diálogo entre los estudiantes, quienes algunas veces por las conductas del docentes cohíben la participación generando en ellos una cadena de inquietudes que puede perjudicar más adelante. De allí, Hughes (1983); Benkler (2006); Castell y Tubella (2007), asumen el uso del internet como un mecanismo para masificar la información y que el conocimiento llegues a todos sin importar la ubicación geográfica para culturizar el pensamiento $y$, por ende, el vocabulario.

De lo antes mencionado, las instituciones de educación universitaria en conjunto con los ministerios que forman parte de su organización departamental atendiendo a sus múltiples tareas o funciones han diseñado e implementado políticas públicas y educativas que conduzcan a la producción de la ciencia y la tecnología a fin de promover competencias digitales tanto en docentes como estudiantes, dentro de estas tenemos las Canaima en su presentación portátil y tableta, las cuales traen consigo materiales didácticos para facilitar el trabajo de los estudiantes, a su vez, se han instalado redes inalámbricas (wifi) en plazas públicas para acercar a los actores sociales al mundo del conocimiento.

\subsection{Humanidad digital: componentes esenciales en el intercambio e interacción comunicativa en las universidades nacionales}

La humanidad en la nueva dimensión tecnológica contribuye en la creación y diseño de estrategia 
que potencien las variables de la comunicación con la intencionalidad de mantener informado de manera eficaz y significativa a la población docente como estudiantil, por ello, el cerebro junto a sus órganos garantizan situaciones o experiencias para identificar, observar y comprender las texturas, colores, formas, entre otras características de las diferentes imágenes, sonidos que pueda percibir para exponer ideas o formas de pensamiento. Por otra parte, al producir señales a través de información estas se traducen en el desarrollo de habilidades cognitivas como la memoria, razonamiento, planificación coadyuva a las configuraciones de imágenes mentales.

Por consiguiente, el cerebro procesa estímulos que recibe del cuerpo y del entorno con el objetivo último de garantizar la supervivencia y aumentar el bienestar del dueño del cerebro. Es por ello que, las imágenes mentales se generan mediante la interacción entre regiones concretas del cerebro y del cuerpo que responden a estímulos internos y externos, trayendo como consecuencia respuestas coherentes y congruentes a los diferentes estímulos provocados por el cerebro y el conjunto de neuronas que procesan cantidades de información, las cuales conllevan a la racionalización, critica, reflexión, entendimiento y comprensión de las acciones humanas, tal como lo menciona Schooler y cols., (2011), quienes exponen que el cerebro cuando genera conexiones sinápticas entre las neuronas a través de neurotransmisores facilita la ejecución de tareas producto de señale sensoriales que conducen al procesamiento estímulos externos.

De lo antes expuesto, se resalta que es importante que las universidades fomenten el desarrollo del pensamiento activando los procesos neuronales, los cuales provocan la reacción sináptica para activar ambos hemisferios, de este modo, Lakoff (2008:40), enuncia que las actividades o el arte de comunicar representa una función natural del ser humano para ejercer sus tareas personales, laborales como procesionales para producir conexión sináptica mediante redes neuronales que orienten el trabajo cooperativo entre las organizaciones de educación universitarias. Esto se debe a que "cuando vivimos una narración, y cuando vemos a otro viviendo esa narración, se utiliza una parte de la misma estructura neuronal del cerebro".

De igual forma, el cerebro capta los sentimientos y emociones que se derivan de estímulos percibidos por los sentidos, los cuales, al hacer contacto con las neuronas, estas los procesan y hacen que sean explícitos, pudiéndose expresar a través de acciones, las misma a su vez reflejan factores que ejercen fuerza en el poder de los actores sociales tales como la dominación, manipulación y control que van a depender de la fijación de estas características humanas en cada individuo. Es así como los gerentes o gestores como miembros principales de una organización pueden influir positiva o negativamente en ellos dependiendo del manejo de la inteligencia emocional.

Por otra parte, Lakoff (2008), menciona que el enmarcado no es una cuestión de eslóganes; es una forma de pensar y actuar. Por lo que no es sólo palabras, aunque las palabras o las imágenes sean necesarias para construir el marco y comunicarlo, lo fundamental es que los marcos no están fuera de la mente y, a su vez, son capaces de conectar el mensaje con los marcos mentales preexistentes convirtiéndose en un activado de redes de la conducta. En este sentido, Entman (2004) sostiene que los marcos que emplean términos con mayores resonancias culturales tienen mayores posibilidades de influir: palabras e imágenes que llaman la atención, son comprensibles, fáciles de recordar y que incluyen una carga emocional. 
Por todo ello, la UNERMB, no escapa de esta realidad donde existe el poder como pate de dominar en un instancia a los estudiantes quienes muchas veces se ven afectados por las formas de evaluar de sus docentes donde solamente exponen que no está bien o por el contrario, exponen que nada de lo elaborado tiene relevancia, por otro lado, entre los mismos docentes, de la manera que interpelan al nuevo o el recién graduado a ver si en verdad posee conocimientos o si se ha memorizado textos, de esta forma miden el conocimiento, además, los procesos comunicativos en algunos casos es unidireccional lo que limita a los educandos a su capacidad de análisis, su participación y creación de experiencias de aprendizaje satisfactorias. Por tal motivo, se hace necesario que los docentes colaboren en hacer que sus estudiantes piensen razonablemente para desarrollar su poder mental y con ello cognitivo.

\section{Metodología}

El desarrollo de esta investigación se basó en un producto con enfoque cualitativo sustentado en Miguélez (2000), así mismo, un paradigma interpretativo y un método fenomenológico fundamentado en Heidegger (2006) y Husserl (1998), posteriormente se aplicó como instrumento la entrevista del tipo semiestructurado a tres (03) docentes del programa educación discriminados de la siguiente manera: uno de ciencias sociales, uno de ciencias pedagógicas y uno de práctica profesional.

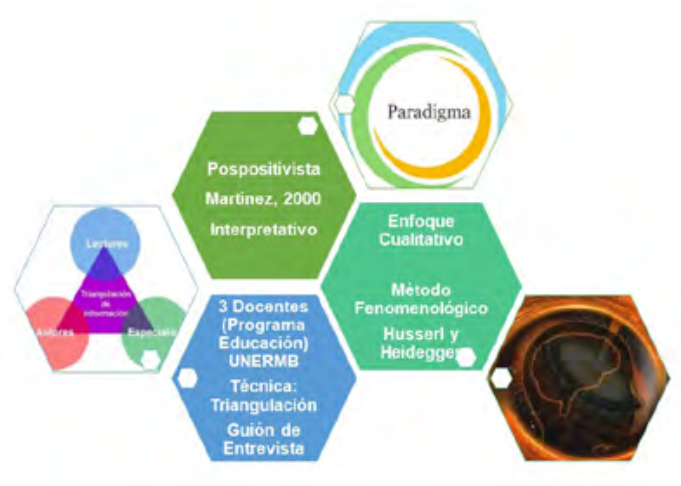

Figura 1. Entramado metodológico

Fuente: elaboración propia 


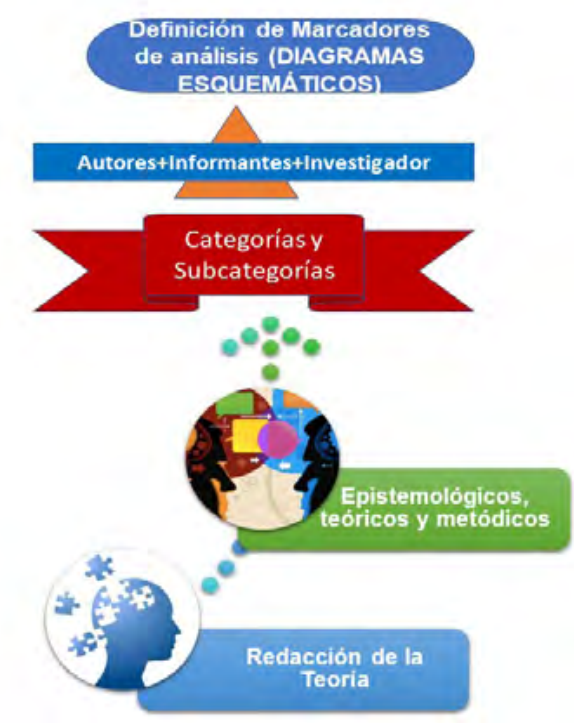

Figura 2. Delimitación para la discusión de los datos

Fuente: elaboración propia

\section{Resultados}

Luego de la aplicación de técnicas e instrumentos a los informantes claves, quienes se mencionan con un atributo de identificación anónima conservando los criterios éticos de la confidencialidad en las investigaciones cualitativas, en este sentido, entre los seleccionados como unidades de análisis se obtienen los siguientes resultados:

En cuanto al informante identificado con el atributo de las siglas (PP), se observó que existe incongruencia con el hacer y su saber, debido a que en su discurso durante el dialogo promovido por la entrevista, este manifestó la necesidad de emplear la lectura como una actividad para fomentar el pensamiento desde la investigación, la cual representa una herramienta viable en las practicas críticas y reflexivas que junto al dialogo generan producción de conocimientos.

Seguidamente, el informante identificado con las siglas (CS) expuso desarrollar actividades y estrategias que contribuyan el pensamiento crítico de los estudiantes donde estos pudieran expresar sus ideas, acerca de las teorías estudiadas según el área, en ese sentido, afirmó que la construcción de saberes parten de un buen plan de formación centrado en el dialogo como visión epistemológica del aprendizaje, en concordancia con lo observado por el investigador, algunas veces este emplea técnicas abiertas pero manteniendo su postura en el discurso de los trabajos demarcando su estilo en pensar y escribir.

Por último, el informante identificado con las siglas (CP), afirmó que es importante que los docentes reflexionen sobre su práctica y acción didáctica a fin de poder autoevaluarse, razón que conlleva a generar nuevas estrategias desde una visión innovadora, creativa y emancipadora del aprendizaje, afianzando así herramientas metodológica donde los estudiantes puedan generar 
ciencia desde sus habilidades y realidad directa en relación a su área profesional, en cuanto a sus respuestas este informante casi siempre aplica foros, debates, entre otros,, donde escucha libremente, donde su participación se debe a fundamentar de mejor manera todas las ideas expuestas.

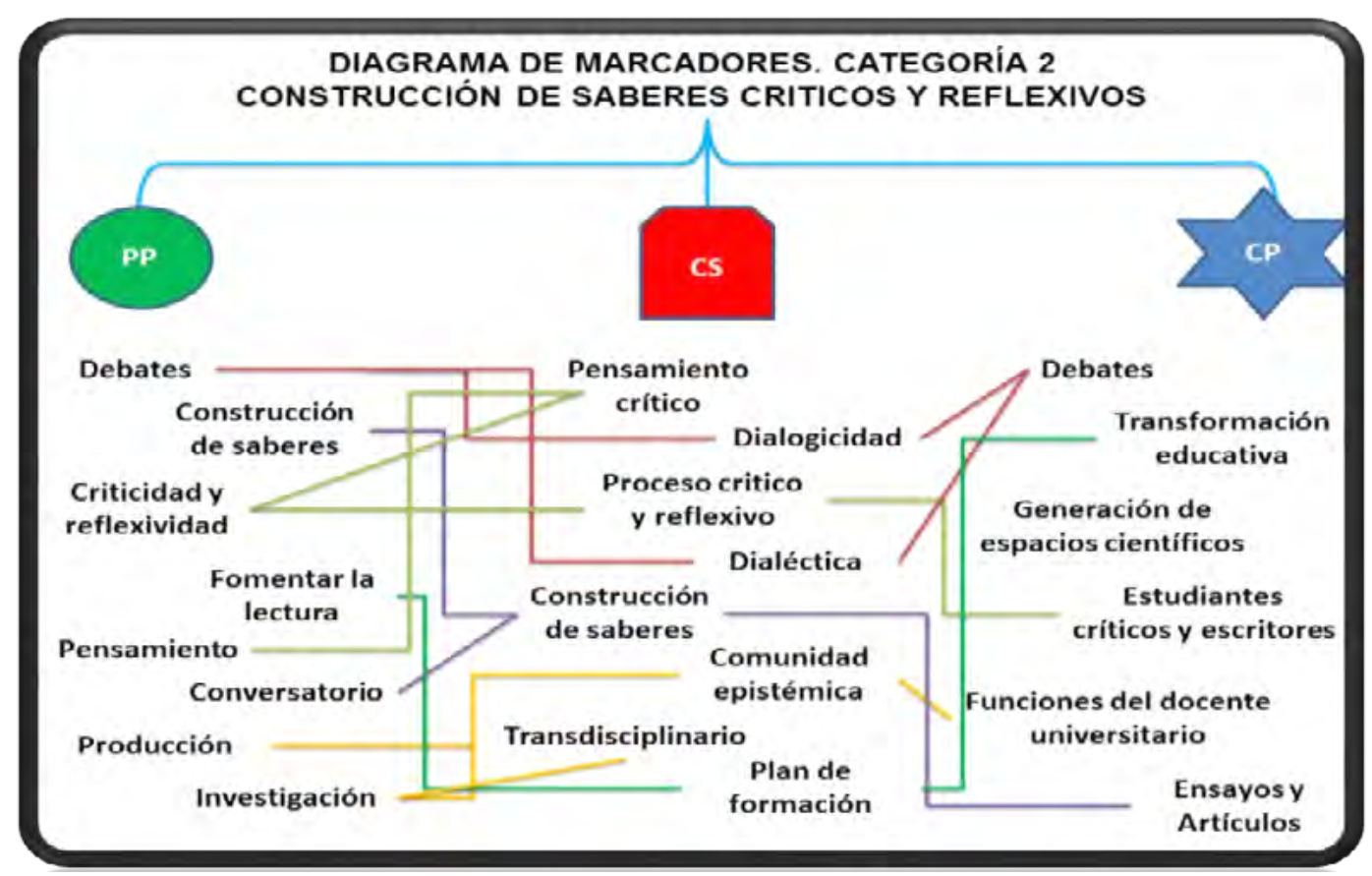

Figura 3. Discusión: categoría 2

Fuente: elaboración propia

\section{Conclusiones}

Considerando como propósito principal el develar la filosofía universitaria como una corriente para la construcción de significados en la formación de formadores, se observó que muchos de los docentes hacen uso incorrecto del poder en sus aulas, pues esta actitud conlleva a los estudiantes a realizar sus actividades de forma limitada, puesto que se les impone la estructura y el discurso, entre otros factores cognitivos.

De igual forma, desarrollan procesos pocos dinámicos, lo que conlleva a una formación centrada en una corriente tradicional, solo algunas veces enfocan actividades para promover la construcción de saberes, la cual se ve debilitada a instrucciones expuestas e impuestas por él, fijando siempre su poder para controlar la forma en cómo se deben realizar ciertas investigaciones.

Al respecto, se concluye que las herramientas para un aprendizaje y enseñanza casi nunca conllevan a reflexionar sobre la actuación del docente, como del estudiante, por su parte, la formación carece de estrategias para el enseñar a pensar desde el aprender a ser, aprender hacer y aprender a aprender, generando entonces propuestas transformadoras en concordancia con las políticas educativas emanadas por el Estado venezolano. 


\section{Referencias}

Benkler, Y. (2006). The wealth of networks: How social production transforms markets and freedom. Yale University Press.

Castells, M. (2009). Comunicación y poder. Madrid: Alianza Editorial, 679 p. Traducción de María Hernández. ISBN 978-84-206-8499-4. https://www.felsemiotica.com/descargas/Castells-Manuel-Comunicaci\%C3\%B3n-y-poder.pdf

Entman, R. (2004). Projections of power, framing news, public opinion and U.S. Foreing Polic., Chicago: University of Chicago Press. DOI:10.7208/chicago/9780226210735.001.0001

Habermas, J. (1976): Legitimationsprobleme im modernen Staat. In Legitimations probleme politischer Systeme (pp. 39-61). VS Verlag für Sozialwissenschaften, Wiesbaden.

Heidegger, M. (2006). Introducción a la fenomenología de la religión. Primera edición en español. México: Fondo de Cultura Económica. Ediciones Siruela S.A.

Hughes, T. P. (1983). Networks of power: electrification in western society, 1880-1930. Baltimore, Johns Hopkins University Press

Husserl, E. (1998). Invitación a la fenomenología. La filosofía como autorreflexión de la humanidad.

Lakoff, G. (2008). The neural theory of metaphor. En Raymond Gibbs (Ed.), The Cambridge handbook of metaphor and thought (pp. 17-38). Nueva York: Cambridge University Press.

Miguélez, M. M. (2000). Origen, auge y ocaso del método científico tradicional en las ciencias humanas. Anthropos: publicación del Instituto Superior Salesiano de Filosofía y Educación, (40), 7-36.

Mokyr, J. (1990) The Lever of Riches -Technological Creativity and Economic Progress. Oxford University (Ed. caso: La palanca de la riqueza, Madrid, Alianza Editorial, 1993).

Monge, P. R., Contractor, N. S., Contractor, P. S., Peter, R., \& Noshir, S. (2003). Theories of communication networks. Oxford University Press, USA.

Schiller, D. (2006). How to think about information. University of Illinois Press.

Schooler, J. W., Smallwood, J., Christoff, K., Handy, T. C., Reichle, E. D., y Sayette, M. A. (2011). Meta-awareness, perceptual decoupling and the wandering mind. Trends in Cognitive Science, 15, 319-326. 
Copyright (c) 2021 Henry Jose Martínez Gonzalez, Duglas Ramón Piña Madueño y Juhenni Maria Martínez Gonzalez

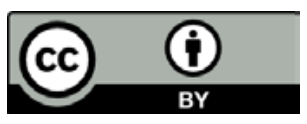

Este texto está protegido bajo una licencia internacional Creative Commons 4.0.

Usted es libre para Compartir-copiar y redistribuir el material en cualquier medio o formato

- y Adaptar el documento - remezclar, transformar y crear a partir del material-para cualquier propósito, incluso para fines comerciales, siempre que cumpla las condiciones de Atribución. Usted debe dar crédito a la obra original de manera adecuada, proporcionar un enlace a la licencia, e indicar si se han realizado cambios. Puede hacerlo en cualquier forma razonable, pero no de forma tal que sugiera que tiene el apoyo del licenciante o lo recibe por el uso que hace de la obra.

\section{$\underline{\text { Resumen de licencia - Texto completo de la licencia }}$}

